\title{
Effect of Febrile State on Theophylline Clearance in Asthmatic Acute Phase in Japanese Pediatric Patients
}

\author{
Tsutomu Igarashi ${ }^{* 1}$ and Seigo Iwakawa ${ }^{2}$ \\ Department of Pharmacy, Itami City Hospital ${ }^{1}$, \\ Department of Pharmaceutics, Kobe Pharmaceutical University ${ }^{2}$ \\ $\left[\begin{array}{l}\text { Received October 6, } 2013 \\ \text { Accepted December 26, } 2013\end{array}\right]$
}

The effect of a febrile state on theophylline clearance in the asthmatic acute phase was quantitatively investigated in 71 Japanese pediatric patients (42 males and 29 females) aged $2-<7$ years old. Theophylline clearance from each patient was estimated from the plasma steady-state theophylline concentration, which was retrospectively collected during constant-rate infusion of aminophylline. Theophylline clearances were grouped by the presence of a febrile state, and then these were compared in the same gender groups. In male pediatric patients, theophylline clearance during the febrile state was approximately $71 \%(P<0.001)$ of that during the afebrile state in the asthmatic acute phase. Similarly, in female pediatric patients, it was $85 \%(P<0.05)$ of that during the afebrile state in the asthmatic acute phase. Our findings suggest that the dose of theophylline in Japanese infants should be reduced during a febrile state in the asthmatic acute phase. However, we found some patients whose theophylline clearance in the asthmatic acute phase with fever was more than 50\% lower compared with the theophylline clearance in the asthmatic assumed-remission phase without fever. Therefore, as for the degree of dose reduction during a febrile state from the asthmatic remission phase, the effects of both febrile state and asthmatic acute phase should be simultaneously considered. We propose that the initial dose of theophylline during a febrile state in the asthmatic acute phase should be reduced by half of the dose in the asthmatic remission phase without fever, similarly to the recommendation of the American Academy of Pediatrics.

Key words — theophylline, therapeutic drug management, children, clearance, febrile state, pharmacokinetics

\section{Introduction}

Theophylline is used as an additional treatment drug for children in the asthmatic acute phase, ${ }^{1-3)}$ although the prescription frequency of this drug for children has declined because of concerns about serious adverse effects. ${ }^{4}$ Therapeutic and toxic effects of theophylline are related to its plasma concentration, ${ }^{5-7)}$ and the clearance of theophylline varies with numerous factors, such as age, gender, concurrent drugs and complicating diseases. ${ }^{4,5,7,8)}$

An acute febrile state in children may alter theophylline clearance and can lead to toxic results due to its high plasma level. ${ }^{9-11)}$ Chang et al re- ported that acute respiratory viral illness with fever reduced theophylline elimination in six children with chronic asthma. ${ }^{9}$ Kraemer et al reported that eleven children with febrile illness, who were previously controlled with a stable theophylline dose, developed theophylline toxicity during an influenza B outbreak. ${ }^{10)}$ However, Muslow et al reported the lack of an effect of respiratory syncytial virus on theophylline disposition in children without sustained fever. ${ }^{12)}$ Therefore, the American Academy of Pediatrics describes that fever is considered to be a more practical clinical indication than a specific etiologic agent for reducing the theophylline dose, and recommends that the dosage should be reduced by half in chil-

* 1-100, Koyaike, Itami, Hyogo 664-8540, Japan 
dren receiving chronic theophylline therapy who are febrile for more than 24 hours. ${ }^{13)}$ However, it is unclear whether theophylline clearance is affected quantitatively equally by a febrile state in all children without regard to race, age, and/or gender. $^{7,8,14)}$

In regard to Japanese children, Toba et al reported that the theophylline clearance was reduced by $25 \%$ on average in children with febrile infections aged 1 to 13.5 years. ${ }^{15)}$ Imai et al reported the theophylline clearance to be decreased by $23 \%$ on average in children with pyrexia aged 3 months to 2.9 years. ${ }^{16)}$ These results do not support the recommendation of the American Academy of Pediatrics, and these studies do not consider the influence of gender. Besides, available data about the quantitative effect of a febrile state on theophylline clearance are limited, particularly in children under school age who should receive careful dosing of theophylline in the asthmatic acute phase. ${ }^{17)}$ Previously, we reported the effect of gender on theophylline clearance in the asthmatic acute phase and the effect of asthmatic acute phase on theophylline clearance during constant aminophylline infusion in Japanese pediatric patients. ${ }^{8}$ (18) The purpose of this report is to investigate the quantitative effect of a febrile state on theophylline clearance in the asthmatic acute phase in Japanese male and female infants.

\section{Materials \& Methods}

\section{Patients}

We retrospectively investigated theophylline clearance in 71 Japanese pediatric patients (42 males and 29 females) in the asthmatic acute phase ranging in age from 2.0 to 6.9 years and in weight from 10.0 to $23.6 \mathrm{~kg}$. All patients were admitted as emergency cases to Itami City Hospital because of acute airway obstruction and received intravenous constant-rate infusions of aminophylline (Neophylline; Eisai Co, Ltd, Tokyo, Japan). The data from the patients in the asthmatic acute phase were retrospectively collected from routine clinical records. This study covered the period from January 2001 to December 2004, when theophylline was commonly used, and was approved by the Ethics Committee of Itami City Hospital (approval No 41), which was instituted on June 1, 1999. We performed our study in accordance with the ethical guidelines for epidemiological research. Most patients had received a few inhalations of salbutamol and an intravenous loading bolus of aminophylline before admission. After admission, aminophylline mixed with transfusion fluids (Na $35 \mathrm{mEq} / \mathrm{L}, \mathrm{K} 20 \mathrm{mEq} / \mathrm{L}, \mathrm{Cl} 35 \mathrm{mEq} / \mathrm{L}$, lactate $20 \mathrm{mEq} / \mathrm{L}$, and glucose $4.3 \%$ ) was given using an STC-508 constant infusion pump (Terumo Corporation, Tokyo, Japan), and the constant infusion rate of aminophylline was adjusted appropriately by pediatricians following the therapeutic drug monitoring of theophylline. These patients received additional medication, such as antibiotics, systemic steroids, salbutamol inhalations, oxygen supply, and anti-tussives, as determined by pediatricians. No subjects showed serious airway disorders such as respiratory failure. The demographic and medication data of the male and female pediatric patients are shown in Table 1.

\section{Patient data}

Patient data were collected by reviewing medical records, which included medical history, clinical progress, laboratory data, body temperature, concurrent drugs, and the time records of administered drugs. Criteria for the selection of theophylline clearance comprised data on patients who had correctly received an intravenous constant- 
Table 1 Demographic and medication data of male and female patients aged $2-<7$ years in asthmatic acute phase

\begin{tabular}{|c|c|c|c|c|c|c|}
\hline \multirow{2}{*}{$\begin{array}{l}\text { Gender Group } \\
\text { Febrile state }\end{array}$} & \multicolumn{2}{|c|}{ Males } & \multicolumn{2}{|c|}{ Females } & \multicolumn{2}{|c|}{ Total } \\
\hline & + & - & + & - & + & - \\
\hline Number of patients & 13 & $34^{a)}$ & 12 & $19^{b)}$ & 25 & $53^{c)}$ \\
\hline (with 1 measurement) & 12 & 29 & 10 & 15 & 22 & 44 \\
\hline (with 2 measurements) & 1 & 5 & 1 & 3 & 2 & 8 \\
\hline (with 3 measurements) & & & 1 & & 1 & \\
\hline (with $>3$ measurements) & & & & 1 & & 1 \\
\hline Total number of measurements & 14 & 39 & 15 & 26 & 29 & 65 \\
\hline Age $(\text { years })^{1)}$ & $3.9 \pm 1.0$ & $3.6 \pm 1.1$ & $3.7 \pm 1.7$ & $3.7 \pm 1.2$ & $3.8 \pm 1.4$ & $3.7 \pm 1.2$ \\
\hline Weight $(\mathrm{kg})^{1)}$ & $16.1 \pm 2.2$ & $15.1 \pm 3.5$ & $14.7 \pm 3.9$ & $14.3 \pm 1.7$ & $15.4 \pm 3.1$ & $14.8 \pm 3.0$ \\
\hline Duration of hospital stay $(d)^{1)}$ & $5.9 \pm 1.4$ & $6.3 \pm 1.9$ & $7.1 \pm 2.8$ & $6.6 \pm 2.5$ & $6.5 \pm 2.2$ & $6.4 \pm 2.1$ \\
\hline Infusion rate of theophylline $(\mathrm{mg} / \mathrm{h} / \mathrm{kg})^{1)}$ & $0.58 \pm 0.08$ & $0.59 \pm 0.08$ & $0.55 \pm 0.09$ & $0.58 \pm 0.08$ & $0.57 \pm 0.08$ & $0.58 \pm 0.08$ \\
\hline Sampling time after initiation of infusion $(\mathrm{h})^{1)}$ & $22.8 \pm 7.4$ & $25.3 \pm 8.4$ & $23.2 \pm 5.5$ & $27.3 \pm 8.7$ & $23.0 \pm 6.4$ & $26.0 \pm 8.5$ \\
\hline Concentration of theophylline $(\mu \mathrm{g} / \mathrm{mL})^{1)}$ & $14.0 \pm 3.5$ & $10.4 \pm 2.7^{*}$ & $13.0 \pm 3.3$ & $11.4 \pm 2.1$ & $13.5 \pm 3.4$ & $10.7 \pm 2.5^{* *}$ \\
\hline Concentration range of theophylline $(\mu \mathrm{g} / \mathrm{mL})$ & $9.8-21.0$ & $3.3-15.0$ & $7.4-19.6$ & $6.6-14.8$ & $7.4-21.0$ & $3.3-15.0$ \\
\hline \multicolumn{7}{|l|}{ Loading bolus dose of theophylline $(\mathrm{mg} / \mathrm{kg})^{2)}$} \\
\hline $5-<6$ & & 3 & & & & 3 \\
\hline $4-<5$ & 3 & 5 & & 2 & 3 & 7 \\
\hline $3-<4$ & 3 & 9 & 5 & 5 & 8 & 14 \\
\hline $2-<3$ & 3 & 16 & 7 & 13 & 10 & 29 \\
\hline $1-<2$ & 2 & 2 & & 2 & 2 & 4 \\
\hline no dose & 3 & 4 & 3 & 4 & 6 & 8 \\
\hline \multicolumn{7}{|l|}{ Concurrently used drugs ${ }^{3)}$} \\
\hline Antibiotics (intravenous) ${ }^{4)}$ & 14 & 27 & 15 & 20 & 29 & 47 \\
\hline Prednisolone (intravenous) & 2 & 12 & 1 & 13 & 3 & 25 \\
\hline Oxygen supply & 2 & 9 & 0 & 6 & 2 & 15 \\
\hline Salbutamol (inhalation) & 14 & 38 & 15 & 26 & 29 & 64 \\
\hline Terbutaline (oral) & 10 & 28 & 13 & 18 & 23 & 46 \\
\hline
\end{tabular}

a) Included 5 same patients who were febrile. $b$ ) Included 2 same patients who were febrile. $c$ ) Included 7 same patients who were febrile. 1) Data are the Mean \pm SD. 2) Data are the number of cases. Loading bolus doses were determined by pediatricians according to the serum level of theophylline and/or the compliance with oral theophylline before the bolus. 3) Data are the number of cases concurrently using the indicated drugs. 4) Cefotiam dihydrochloride and clindamycin phosphate were the most frequently used antibiotics. 5) Oxygen was supplied via a face mask or nasal cannula. ${ }^{*} P$ $<0.001$ vs the mean during febrile state in same gender group, by Student's $t$-test. ${ }^{* *} P<0.001$ vs the mean during febrile state in same gender group, by Welch's test.

rate infusion of aminophylline and then had their steady-state theophylline concentration measured. The theophylline concentration measured within 48 hours after the initiation of continuous aminophylline infusion was defined as the concentration in the asthmatic acute phase and was used, since it has been reported that appreciable changes in theophylline clearance could occur in children with acute asthma within a few days (at least 72 hours). ${ }^{19)}$ The theophylline clearance of the following patients was excluded: 1) if the patient had been diagnosed with hepatic dysfunction, renal dysfunction, congestive heart failure, or congenital disease, 2) if the patient was concurrently receiving drugs regarded as affecting theophylline clearance, such as erythromycin, clarithromycin, or phenobarbital, and 3) if the patient had been administered oral theophylline within 24 hours before estimating theophylline clearance.

Eligible theophylline clearances were divided by the presence of a febrile state, and then these were studied. A febrile state was confirmed by a body temperature of more than $38^{\circ} \mathrm{C}$ measured two times or more with an interval of 3 hours or more, or a body temperature of more than $38^{\circ} \mathrm{C}$ and C-reactive protein of more than $0.5 \mathrm{mg} / \mathrm{dL}$, within 24 hours before estimating. These definitions of a febrile state were based on a report by 
Toba et $a l .{ }^{15)}$ The pathogens that could have triggered a fever were not identified because of the lack of data provided by seroconversion or cultivation. No subjects had severe infections such as sepsis.

\section{Estimation of theophylline clearance}

The theophylline clearance $(\mathrm{mL} / \mathrm{h} / \mathrm{kg})$ of each patient was calculated using the following formula: clearance $=10^{3} \times \mathrm{R} / \mathrm{Css}$, where $\mathrm{R}$ is the constant infusion rate of the dose of theophylline $(\mathrm{mg} / \mathrm{h} / \mathrm{kg})$ and Css is the steady-state concentration of theophylline $(\mathrm{mg} / \mathrm{L})$. The steady-state concentration is usually achieved after four halflives following constant infusion. ${ }^{20)}$ Since the elimination half-life of theophylline is approximately 4 hours for pediatric patients, the steadystate concentration was assessed more than 16 hours after the initiation of constant-rate infusion of aminophylline. ${ }^{21)}$ However, Chang et al reported that the mean plasma theophylline half-life was about 7 hours during febrile respiratory illness. ${ }^{9)}$ Therefore, if the patient had received neither regular oral theophylline nor loading bolus of aminophylline before admission, a steady-state concentration of theophylline during a febrile state in the asthmatic acute phase was required for more than 28 hours after the initiation of a constant-rate infusion of aminophylline. On admission, most patients were considered to be approaching the steady state because of the previously administered loading bolus of aminophylline.

Serum concentrations of theophylline were determined by a fluorescence polarization immunoassay $\left(\mathrm{TDX}^{\mathrm{TM}}\right.$ theophylline assay system; Abbott Japan Co, Ltd, Tokyo, Japan). The detection range of the theophylline immunoassay was 0.82 to $40 \mu \mathrm{g} / \mathrm{mL}$ (package insert of the reagent pack;
TDX $^{\mathrm{TM}}$ Theophylline Monoclonal II, Abbott Japan Co, Ltd, February 2003).

\section{Comparison and statistical analysis}

Comparisons of mean theophylline clearances were performed in the same gender groups. If theophylline clearance was calculated more than once for one patient, the clearance was averaged for the patient in each group. Statistical analysis was performed using Statcel 2 software (OMS Publishing Inc, Tokorozawa, Japan) installed in Microsoft Excel. The normality of the clearance in each group was assessed using chi-square test for goodness of fit. The significance of the difference of theophylline clearance and physiologic characteristics of the patients were analyzed with unpaired Student's $t$-test or Welch's test, and with a two-sided test.

In addition, for the purpose of estimating the intra-patient effect of the febrile state on theophylline clearance, we investigated theophylline clearances during a febrile state and during an afebrile state in the same patients. Previously, we demonstrated that theophylline clearance estimated at more than 60 hours was higher than that estimated within 48 hours after the initiation of aminophylline infusion in the asthmatic acute phase in children without fever. ${ }^{18)}$ We also suggested that the increasing change of theophylline clearance in our previous study was comparable to the change of theophylline clearance during the phase from an attack to remission in asthmatic children in Odajima's study. ${ }^{22}$ Therefore, we additionally employed and investigated the theophylline clearance estimated at more than 60 hours after the initiation of aminophylline infusion in estimating the intra-patient effect of the febrile state, as a substitute for theophylline clearance in the asthmatic remission phase without fever. 


\section{Results}

Theophylline clearances of pediatric patients during a febrile state and an afebrile state in the asthmatic acute phase are shown in Fig 1. In male pediatric patients, theophylline clearances during a febrile state and an afebrile state were $42.8 \pm 8.1$ ( $71 \%$ of the value of an afebrile state: $P<0.001)$ and $60.5 \pm 17.2 \mathrm{~mL} / \mathrm{h} / \mathrm{kg}$, respectively. Similarly, in female pediatric patients, theophylline clearances in these groups were $44.2 \pm 8.0$ ( $85 \%$ of the value of an afebrile state: $P<0.05$ ) and $52.2 \pm 11.8 \mathrm{~mL} / \mathrm{h} / \mathrm{kg}$. The effect of a febrile state on theophylline clearance was greater in males than in females. Theophylline clearance during a febrile state in the asthmatic acute phase showed a similar value regardless of gender. With regard to the physiologic characteristics of the patients, insignificant differences were observed except for the concentrations of theophylline among the male and total gender groups (Table 1).

As for the intra-individual effect of the febrile

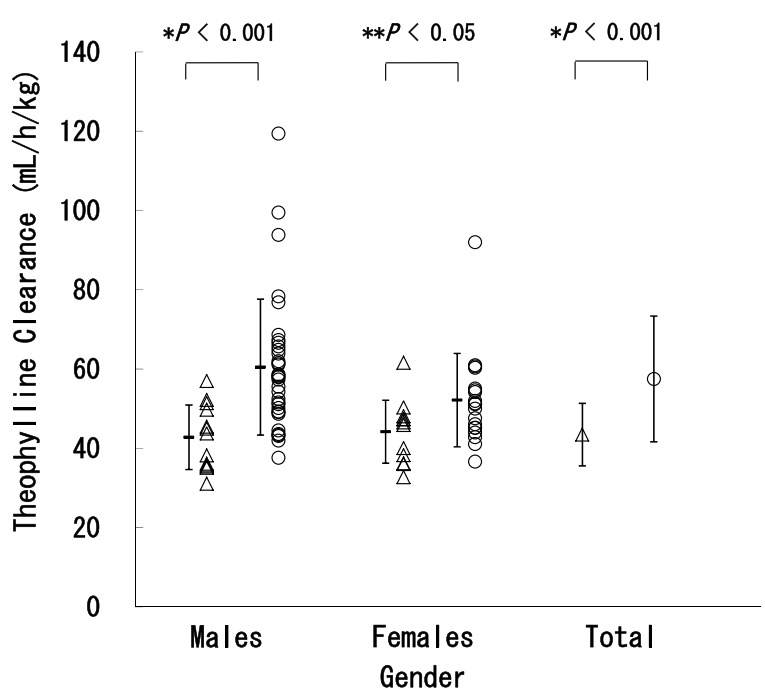

Fig 1 Effect of a febrile state on theophylline clearance in male and female pediatric patients in the asthmatic acute phase

Each symbol represents the value of theophylline clearance for each patient. Bars represent the Mean $\pm \mathrm{SD}$. $\triangle$ theophylline clearance during a febrile state; $\bigcirc$ theophylline clearance during an afebrile state. * Welch's test, ${ }^{* *}$ Student's $t$-test. state, in four cases (patient No 4, 6, 8, 12), the theophylline clearances during a febrile state decreased by nearly $50 \%$ or more compared to the theophylline clearances during an afebrile state estimated at more than 60 hours after the initiation of aminophylline infusion (Table 2). Statistical analysis was not performed so that we could not rule out the effects of the age-dependent and dose-dependent kinetics of theophylline due to the variation of age and/or administering rate.

\section{Discussion}

In this study, we have shown a significant effect of a febrile state on theophylline clearance in the asthmatic acute phase in Japanese children aged 2 $<7$ years old. Our findings suggest that the dose of theophylline should be reduced during a febrile state in the asthmatic acute phase. The reductions of mean theophylline clearance during a febrile state in the asthmatic acute phase were approximately $29 \%$ in male patients and $15 \%$ in female patients. Our results are comparable with those in a report by Toba $e t a l$, in which the average reduction of theophylline clearance was $25 \%$ in febrile infections in children aged 1 to 13.5 years. ${ }^{15}$

Chang et al reported that the plasma half-life of theophylline was 7 hours during the acute stage of febrile illness in six children, compared with 4.2 hours at 1 month after illness. ${ }^{9)}$ Kraemer et al reported on febrile children whose plasma concentration of theophylline increased twofold or more during an influenza B outbreak. ${ }^{10}$ They compared theophylline clearance during a febrile state in the asthmatic acute phase with that during an afebrile state in the asthmatic remission phase and showed the theophylline clearance to be decreased by approximately half. Thus, the difference in the decreased value of theophylline clear- 
ance may be resulted from the comparison method of theophylline clearance between these reports and our study, although we compared theophylline clearances in the asthmatic acute phase. However, in the intra-individual changes of theophylline clearance, we observed the cases that the theophylline clearance decreased by half during a febrile state from the assumed-remission phase. In these cases, although the effects of the age-dependent and/or dose-dependent kinetics might be involved in altering the clearance, the theophylline clearances of patient No 6 and No 8 decreased approximately by half at almost the same age and the same administering rate (Table 2). Therefore, as for the dose reduction during a febrile state in the asthmatic acute phase from the asthmatic remission phase without fever, the effects of a febrile state and the asthmatic acute phase should be simultaneously considered for safe management during theophylline administration. We propose that the initial dose of theophylline in the asthmatic acute phase with fever should be reduced by half of the dose in the asth- matic remission phase without fever, similarly to the recommendation of the American Academy of Pediatrics. However, in Japanese Pediatric Guideline of the Treatment and Management of Asthma $2012,{ }^{23)}$ the details of theophylline clearance decreasing during a febrile state and/or an asthmatic attack state are insufficient for the safe management of dosing theophylline.

Theophylline clearance varies with physiologic, pathogenic, and drug-related factors. Therefore, when the effect of a febrile state on theophylline clearance is investigated, these effects on theophylline clearance should be considered. We excluded the data of patients who had complications and/or used drugs reported to affect theophylline clearance, other than in a febrile state. Treatments with prednisolone, oxygen supply, or terbutaline were reported to have no effect on theophylline clearance in our previous study. However, we could not identify infectious pathogens that could trigger a fever and the reduction of theophylline clearance because of the lack of data proved by seroconversion or cultivation. Re-

Table 2 Intra-individual changes of theophylline clearance in the same patients

\begin{tabular}{|c|c|c|c|c|c|c|c|c|c|c|}
\hline \multirow{2}{*}{$\begin{array}{c}\text { Patient } \\
\text { No }\end{array}$} & \multirow{2}{*}{ Gender } & \multicolumn{3}{|c|}{$\begin{array}{l}\text { During febrile state } \\
\text { in asthmatic acute phase } \\
\text { (estimated within } 48 \mathrm{~h} \text { ) }\end{array}$} & \multicolumn{3}{|c|}{$\begin{array}{l}\text { During afebrile state } \\
\text { in asthmatic acute phase } \\
\text { (estimated within } 48 \mathrm{~h} \text { ) }\end{array}$} & \multicolumn{3}{|c|}{$\begin{array}{c}\text { During afebrile state } \\
\text { in asthmatic acute phase } \\
\text { (estimated at more than } 60 \mathrm{~h} \text { ) }\end{array}$} \\
\hline & & $\begin{array}{l}\text { age at } \\
\text { estimating } \\
\text { (years) }\end{array}$ & $\begin{array}{l}\text { infusion rate as } \\
\text { theophylline } \\
(\mathrm{mg} / \mathrm{h} / \mathrm{kg})\end{array}$ & $\begin{array}{l}\text { theophylline } \\
\text { clearance } \\
(\mathrm{mL} / \mathrm{h} / \mathrm{kg})\end{array}$ & $\begin{array}{l}\text { age at } \\
\text { estimating } \\
\text { (years) }\end{array}$ & $\begin{array}{l}\text { infusion rate as } \\
\text { theophylline } \\
(\mathrm{mg} / \mathrm{h} / \mathrm{kg})\end{array}$ & $\begin{array}{l}\text { theophylline } \\
\text { clearance } \\
(\mathrm{mL} / \mathrm{h} / \mathrm{kg})\end{array}$ & $\begin{array}{l}\text { age at } \\
\text { estimating } \\
\text { (years) }\end{array}$ & $\begin{array}{l}\text { infusion rate as } \\
\text { theophylline } \\
(\mathrm{mg} / \mathrm{h} / \mathrm{kg})\end{array}$ & $\begin{array}{l}\text { theophylline } \\
\text { clearance } \\
(\mathrm{mL} / \mathrm{h} / \mathrm{kg})\end{array}$ \\
\hline 1 & M & 2.5 & 0.61 & 35.4 & 4.5 & 0.49 & $49.1^{a)}$ & - & - & - \\
\hline 2 & M & 3.0 & 0.60 & 49.7 & 2.7 & 0.62 & $\mathbf{5 7 . 3 ^ { a ) }}$ & - & - & - \\
\hline 3 & M & 3.4 & 0.63 & 36.1 & 3.4 & 0.63 & $42.0^{b)}$ & - & - & - \\
\hline 4 & M & 4.6 & 0.59 & 52.2 & - & - & - & 4.0 & 0.45 & $99.9^{a)}$ \\
\hline 5 & M & 4.8 & 0.65 & 51.4 & 4.8 & 0.76 & $58.7^{a)}$ & - & - & - \\
\hline 6 & M & 5.1 & 0.44 & 45.0 & - & - & - & 5.1 & 0.44 & $105.5^{b)}$ \\
\hline 7 & M & 5.4 & 0.53 & 45.5 & 4.3 & 0.68 & $64.9^{a)}$ & 4.3 & 0.67 & $71.5^{a)}$ \\
\hline 8 & $\mathrm{~F}$ & 2.5 & 0.45 & 46.5 & 3.0 & 0.56 & $51.3^{a)}$ & 2.6 & 0.46 & $90.7^{a)}$ \\
\hline 9 & $\mathrm{~F}$ & 2.7 & 0.54 & 26.9 & - & - & - & 2.5 & 0.38 & $39.6^{a)}$ \\
\hline 10 & $\mathrm{~F}$ & 2.8 & 0.75 & 50.3 & - & - & - & 2.8 & 0.67 & $78.9^{b)}$ \\
\hline 11 & $\mathrm{~F}$ & 2.9 & 0.64 & 40.1 & 3.8 & 0.42 & $47.6^{b)}$ & 3.8 & 0.42 & $50.9^{a)}$ \\
\hline 12 & $\mathrm{~F}$ & 4.5 & 0.53 & 36.1 & - & - & - & 4.5 & 0.35 & $99.7^{b)}$ \\
\hline Mean & $\pm \mathrm{SD}$ & & & $42.9 \pm 8.0$ & & & $53.0 \pm 7.8$ & & & $79.6 \pm 24.2$ \\
\hline
\end{tabular}


gardless of the type of pathogen that might be related to the degree of the effect on theophylline clearance, the American Academy of Pediatrics described that an acute febrile response per se might be more important in reducing drug metabolism than a specific etiologic agent, as the clearance of antipyrine was reduced in the presence of etiocholanolone -induced noninfectious fever. ${ }^{13,24)}$

The mechanism of reduction of theophylline clearance associated with a febrile state remains to be elucidated, although it has been reported that the administration of external agents such as endotoxin, influenza vaccine, and interferon also reduced drug metabolism. ${ }^{25-29)}$ Yamaguchi et al have suggested that cytokines released during acute illness induce C-reactive protein simultaneously with high body temperature and may suppress the activity of CYP1A2 which is responsible for theophylline metabolism. ${ }^{30}$ Shedlofsky et al reported that the injection of Gram-negative endotoxin caused physiologic responses including fever and cytokine production in human volunteers. ${ }^{25,26)}$ They demonstrated that two administrations of Gram-negative endotoxin on consecutive days caused marked decreases in the clearance of theophylline, but not an administration on one day. ${ }^{25)}$ Okuno et al demonstrated that interferon beta treatment reduced drug-metabolizing activities in the human liver in proportion to decreases in the clearance of theophylline. ${ }^{29)}$ However they reported that no correlation was found between the dose of interferon and the magnitude of decreases in drug-metabolizing activities, and suggested that drug-metabolizing activities had been depressed in patients in whom interferon exhibited a clear antiviral or immunostimulating effect. ${ }^{29}$ Therefore, the duration and/or intensity of their effect may be associated with the degree of the reduction in drug-metabolizing activity.
Additionally, we obtained an important result that theophylline clearance during a febrile state in the asthmatic acute phase showed similar values among the studied groups irrespective of gender. Namely, variations in theophylline clearance during fever were not seen among different gender groups, although theophylline clearance during no fever varied with gender. This might show that theophylline clearance decreased by a certain level of drug-metabolizing activities but not by a certain ratio in the asthmatic acute phase with fever. Meredith et al demonstrated that influenza vaccination caused cytokine production and the depression of theophylline clearance in healthy men, and reported that the degree of depression of theophylline clearance appeared to be greater in subjects with higher prevaccination clearance. ${ }^{27)}$ Williams et al demonstrated that injection of interferon resulted in a reduction of theophylline clearance in 8 of 9 subjects, and reported that the effect of interferon on theophylline elimination was greater in subjects who were fast theophylline metabolizers than in subjects who showed slow theophylline clearance. ${ }^{31}$ This may suggest that more careful dosing of theophylline will be required in children with high theophylline clearance than in children with low theophylline clearance.

In conclusion, we propose that the initial dose of theophylline in the asthmatic acute phase with fever should be reduced by half of the dose in the asthmatic remission phase without fever. Thereafter, the dose of theophylline should be adjusted appropriately based on the therapeutic drug monitoring. In addition, more attention for dose-adjustment and therapeutic drug management of theophylline would be required in boys than in girls and in children with high theophylline clearance than in those with low theophylline clearance. 


\section{References}

1) Yung M, South M, Randomized controlled trial of aminophylline for severe acute asthma, Arch Dis Child, 1998, 79, 405-410.

2) Ream RM, Loftis LL, Albers GM, Becker BA, Lynch RE, Mink RB, Efficacy of IV theophylline in children with severe status asthmaticus, Chest, 2001, 119, 1480-1488.

3) Roberts G, Newsom D, Gomez K, Intravenous salbutamol bolus compared with an aminophylline infusion in children with severe asthma: a randomized controlled trial, Thorax, 2003, 58, 306-310.

4) Self TH, Chafin CC, Soberman JE, Effect of disease states on theophylline serum concentrations: are we still vigilant? Am J Med Sci, 2000, 319, 177-182.

5) Blake K, Kamada AK, “Textbook Of Therapeutics: Drug And Disease Management” 6th ed, ed by Herfindal ET, Gourley DR, Williams \& Wilkins, Baltimore, 1996, pp662-667.

6) Minton NA, Henry JA, Acute and chronic human toxicity of theophylline, Human Exp Toxicol, 1996, 15, 471-481.

7) Ohnishi A, A review of clinical use of theophylline in acute asthma: factors influencing kinetic disposition and drug interactions, Methods Find Exp Clin Pharmacol, 2000, 22, 253-258.

8) Igarashi T, Iwakawa S, Effect of gender on theophylline clearance in the asthmatic acute phase in Japanese pediatric patients, Biol Pharm Bull, 2009, 32, 304-307.

9) Chang KC, Bell TD, Lauer BA, Chai H, Altered theophylline pharmacokinetics during acute respiratory viral illness, Lancet, 1978, 1, 1132-1133.

10) Kraemer MJ, Furukawa CT, Koup JR, Shapiro GG, Pierson WE, Bierman CW, Altered theophylline clearance during an influenza B outbreak, Pediatrics, 1982, 69, 476-480.

11) Koren G, Greenwald M, Decreased theophylline clearance causing toxicity in children during viral epidemics, J Asthma, 1985, 22, 75-79.

12) Muslow HA, Bernard L, Brown RD, Jamison RM, Manno JE, Bocchini JA Jr, Wilson JT, Lack of effect of respiratory syncytial virus infection on theophylline disposition in children, J Pediatr, 1992, 121, 466-471.

13) Academy of Pediatrics Committee on Drugs, Precautions concerning the use of theophylline, Pediatrics, 1992, 89, 781-783.
14) Driscoll MS, Ludden TM, Casto DT, Littlefield LC, Evaluation of theophylline pharmacokinetics in a pediatric population using mixed effects models, $J$ Pharmacokinet Biopharm, 1989, 17, 141-168.

15) Toba T, Kurosaki T, Ohta F, Tamai K, Ikegami H, Saitoh Y, Matsuya Y, Makino K, Asai T, Decreased theophylline clearance in children with acute asthma with concurrent febrile respiratory infection, Arerugi, 1994, 43, 113-119.

16) Imai $K$, Munehisa $Y$, Yoshikuni $Y$, Morita $T$, Nomura H, Kimura Y, Mimaki Y, Kihira K, Influences of pyrexia and age on theophylline clearance in young children with asthma, Hiroshima J Med Sci, 2012, 61, 15-18.

17) Japanese Pediatric Allergic Society, “Japanese Pediatric Guideline for The Treatment and Management of Asthma 2005”, ed by Morikawa A, Nisima S, Kyowa Kikaku Ltd, Tokyo, 2005, pp75-76.

18) Igarashi $T$, Iwakawa $S$, Effect of asthmatic acute phase on theophylline clearance in Japanese pediatric patients during constant aminophylline infusion, Jpn J Pharm Health Care Sci, 2010, 36, 517-522.

19) Kubo M, Odajima Y, Ishizaki T, Kanagawa S, Yamaguchi M, Nagai T, Intraindividual changes in theophylline clearance during constant aminophylline infusion in children with acute asthma, J Pediatr, 1986, 108, 1011-1015.

20) Rowland M, Tozer TN, "Clinical Pharmacokinetics: Concepts and Applications" 2nd ed, ed by Rowland M, Tozer TN, Lea \& Febiger, Philadelphia, 1989, pp63-77.

21) Weinberger $\mathrm{M}$, Hendeles $\mathrm{L}$, Theophylline in asthma, N Engl J Med, 1996, 334, 1380-1388.

22) Odajima Y, Examination of theophylline pharmacokinetics during an attack of bronchial asthma in children, Arerugi, 1992, 41, 22-28.

23) Japanese Pediatric Allergic Society, “Japanese Pediatric Guideline for The Treatment and Management of Asthma 2012”, ed by Hamasaki Y, Kohno Y, Ebisawa M, Kondo N, Kyowa Kikaku Ltd, Tokyo, 2011, pp105-106.

24) Elin RJ, Vesell ES, Wolff SM, Effects of etiocholanolone-induced fever on plasma antipyrine half-lives and metabolic clearance, Clin Pharmacol Ther, 1975, 17, 447-457.

25) Shedlofsky SI, Israel BC, McClain CJ, Hill DB, Blouin RA, Endotoxin administration to humans inhibits hepatic cytochrome P450-mediated drug metabolism, J Clin Invest, 1994, 94, 2209-2214.

26) Shedlofsky SI, Israel BC, Tosheva R, Blouin RA, 
Endotoxin depresses hepatic cytochrome P450-mediated drug metabolism in women, Br J Clin Pharmacol, 1997, 43, 627-632.

27) Meredith CG, Christian CD, Johnson RF, Troxell R, Davis GL, Schenker S, Effects of influenza virus vaccine on hepatic drug metabolism, Clin Pharmacol Ther, 1985, 37, 396-401.

28) Okuno H, Kitao Y, Takasu M, Kano H, Kunieda K, Seki T, Shiozaki Y, Sameshima Y, Depression of drug metabolizing activity in the human liver by interferon-alpha, Eur J Clin Pharmacol, 1990, 39, 365-367.
29) Okuno H, Takasu M, Kano H, Seki T, Shiozaki Y, Inoue $\mathrm{K}$, Depression of drug-metabolizing activity in the human liver by interferon-beta, Hepatology, 1993, 17, 65-69.

30) Yamaguchi A, Tateishi T, Okano Y, Matuda T, Akimoto Y, Miyoshi T, Kobayashi S, Koitabashi Y, Higher incidence of elevated body temperature or increased C-reactive protein level in asthmatic children showing transient reduction of theophylline metabolism, J Clin Pharmacol, 2000, 40, 284-289.

31) Williams SJ, Baird-Lambert JA, Farrell GC, Inhibition of theophylline metabolism by interferon, Lancet, 1987, 8565, 939-941. 